\title{
COMPARISON OF PRIMARY ANGIOPLASTY WITH OR WITHOUT STENT PLACEMENT FOR TREATING SYMPTOMATIC INTRACRANIAL ATHEROSCLEROTIC DISEASES
}

\author{
By \\ Ali Hassanin Ali Hassan ${ }^{1 * A m r}$ El-Sayed Salem ${ }^{2}$, Khalid Mohamed \\ Sobh $^{2}$, Sherief M. Al-Shazly ${ }^{1}$, Mahmoud Galal Ahmed ${ }^{2}$ \\ Department of Neurology, Faculty of Medicine, Al-Azhar University Damietta ${ }^{1}$, Cairo $^{2}$, \\ Egypt
}

*Corresponding Author: Ali Hassanin Ali Hassan, E-mail: dr.ali3012@gmail.com

\begin{abstract}
Background: Intracranial atherosclerosis (ICAS) is one of the main causes of ischemic stroke. The optimal therapy for symptomatic ICAS with stenosis $>70 \%$ is not well established yet. Angioplasty with or without stent has been attempted, with controversial results, which mainly be attributed to intraprocedural adverse events, and a high rate of restenosis or in-stent restenosis.

Objective: To investigate efficacy and safety of primary angioplasty with or without stent placement for management of ICAS diseases by comparing angiographic and clinical outcome of both groups.

Patients and Methods: Data from 59 patients with symptomatic ICAS (70-99\% stenosis) were prospectively collected from the Department of Neurology at Al-Hussein and New Damietta Al-Azhar University Hospitals. Interventional Procedure was performed (primary angioplasty for 19/59 and stent placement for 40/59) according to location and size of stenosis. Data of intraprocedural adverse events and clinical and angiographic follow-up outcomes were analyzed.

Results: A total of 59 patients were included in our study. There were $32(54.2 \%)$ males and 27 (45.7\%) females. The mean age was $63.66 \pm 8.264$. Successful revascularization (Residual stenosis <30\%) was obtained in all patients of the angioplasty group (19/19) compared to $92.5 \%$ of patients in the stent group (Pvalue=.544). Intraprocedural adverse events were significantly higher in the stent-treated group $12 / 40(30 \%)$ than in the angioplasty-treated group $1 / 19(5.3 \%)$. There was no statistical significance between the outcome parameters and type of interventional treatment except in restenosis $(\geq 50 \%)$ at median radiological follow-up of 12.5 months, which was higher in the angioplasty-treated group 6/19 (31.6\%) than in the stent-treated group $3 / 40(7.5 \%)$.
\end{abstract}

Conclusions: Intracranial angioplasty with or without stenting for management of symptomatic intracranial atheromatous disease was associated with a high rate of technical success.

Keywords: Primary angioplasty, Stent replacement, intracranial atherosclerosis, revascularization, Stroke.

\section{INTRODUCTION}

Intracranial atherosclerosis (ICAS) is one of the main causes of ischemic stroke. Patients with symptomatic ICAS are at high risk of recurrent attacks of stroke and dementia. Its prevalence varies among ethnicities, with the highest prevalence in the Asian population (33\% to $37 \%$ of the causes of ischemic stroke) and the lowest prevalence in the Caucasian population (Arenillas, 2011). 
There are many modifiable and nonmodifiable risk factors for ICAS. The most typical modifiable risk factors are hypertension, diabetes mellitus (DM), hyperlipidemia, and smoking. The most typical non-modifiable risk factors are age, race, and sex. The highest rate of development of symptomatic ICAD is between the 6th and 7th decades (Ritz et al., 2014).

There are two major options for the treatment of ICAS, either medical therapy or endovascular interventional therapy (angioplasty with or without stenting). Patients who received medical intervention would still have a high-risk factor of recurrent stroke especially have stenosis with luminal narrowing over $70 \%$ (Mei et al., 2017).

For the high-dose medical therapy group, the annual risk of ischemic stroke in the asymptomatic stenotic intracranial artery was previously reported to be about 11\%-12\%. Moreover, increasing the risk of severe bleeding was reported as the side effect for medical treatment (Maida et., 2020).

Endovascular therapies, including angioplasty, stenting, and the combination of both, had originally emerged as alternative approaches because of the poor prognosis of pharmacotherapy (Clark et al., 2017).

The SAMMPARIS (Stenting and Aggressive Medical Therapy for Preventing Recurrent Stroke in Intracranial Stenosis) trial randomized patients with 70-99 \% internal carotid stenosis who had a TIA or ischemic stroke within 30 days of enrollment to treatment with angioplasty and stenting using the wingspan system in addition to aggressive medical therpy, or to aggressive medical therpy alone and showed that aggressive medical therpy alone was superior to aggressive medical therpy with PTAS (Percutaneous Transluminal Angioplasty and Stenting) utilizing Wingspan self expanding stent (Chimowitz et al., 2011a).

Many publications demonstrate the poor clinical design of the SAMMPRIS study and show criticisms on many points in this trial (Alexander, 2012). Following this trial, many studies have demonstrated much safer intraprocedural results with the stent (Jiang et al., 2011 and Miao et al., 2015). Food and Drug Administration (FDA) mandated post market surveillance study, the Wingspan stent system postmarket surveillance (WEAVE) trial that was the largest on-label enrolment of any stent trial for ICAS in the U.S. to date and has the lowest reported intraprocedural complication rate. It gives a better safety profile than earlier reports and lends support for re-considering stenting as a viable treatment option for patients with symptomatic ICAS (Alexander et al., 2019).

Procedures with angioplasty for treating ICAS have often resulted in arterial recoil and restenosis. Using angioplasty alone or angioplasty with stent placement remains controversial. Our study aimed to compare primary angioplasty with or without stent placement for treating symptomatic intracranial atherosclerotic ICAS diseases according to clinical outcome and rate of restenosis. 


\section{PATIENTS AND METHODS}

This was a prospective study on patients with intracranial stenosis selected from the Department of Neurology, AlHussein and New Damietta Al-Azhar University Hospitals after obtaining informed consents.

Inclusion criteria: We included patients aged from 18-80 years with the following criteria:

1. Symptomatic intracranial stenosis (70\%-99\%) involving the anterior circulation (internal carotid, middle cerebral, Anterior cerebral) with a hard-transient ischemic attack (TIA) or stroke attributable to the territory of the target lesion within the past 30 days.

2. Patients with an ischemic stroke and a 70-99\% intracranial stenosis have Modified Rankin Scale (MRS) $\leq 4$.

3. Patients with at least one stenosis in the target vessel, a stenotic length $\leq 15 \mathrm{~mm}$, and a vessel size $>2.5 \mathrm{~m}$.

4. All patients will have to be fully conscious, fit for the procedure and presents written informed consent.

\section{Exclusion criteria:}

1. Patients cannot receive general anesthesia, angiographic assessment, or at high risk (leading to a stroke or death) in delivering a stent to a stenotic lesion.

2. CT or MRI scans show massive cerebral infarction (beyond half of the MCA territory), intracranial haemorrhage, epidural or subdural haemorrhage, and intracranial brain tumor.
3. Patients present with a hemorrhagic infarction in the 14 days before enrolment, the source of emboli is cardiac in origin or diagnosed with myocardial infarction in the 30 days before enrolment.

4. Unstable neurological status (rapid worsening of the National Institute of Health Stroke Severity Scale [NIHSSS] score increasing $>4$ pointswithin 48 hours before randomization.

5. If there previous stent or angioplasty in the target lesion.

6. Patients have been diagnosed with any of the following no n-atherosclerotic lesions: arterial dissection, moyamoya disease, vasculitis disease, any intracranial infection, any intracranial stenosis associated with cerebrospinal fluid pleocytosis, fibromuscular dysplasia; sickle cell disease, neurofibromatosis, benign angiopathy of the central nervous system, suspected vasospastic process, or suspected embolus.

7. Patients have a modified Rankin scale score $\geq 3$.

The study was passed through the following phases:

Phase (1): Baseline assessment and patient selection (patient with hardtransient ischemic attack (TIA) or stroke attributable to the territory of the target lesion within the past 30 days):

Four hundred and forty two stroke patients were enrolled in the initial assessment. They were subjected to the following:

1. Complete clinical assessment. 
2. Assessment of stroke severity using the NIHSS.

3. Assessment of the disability of affected patient, using Modified Rankin Scale (mRS) Scale.

4. Imaging modalities as CT brain or MRI brain and MRA brain or CT angiography and percent of stenosis was measured using The WarfarinAspirin Symptomatic Intracranial Disease (WASID) criteria.

5. Assessment of risk factors (hypertension, diabetes mellitus, hyperlipidemia, coronary artery disease, cigarette smoking, and history of previous stroke/transient ischemic attack).

After completing this phase, 69 patients fulfilled the study criteria, while 373 patients were excluded. From the selected 69 patients, 10 patients refused to give consent. The remaining 59 passed to the next phase after giving a written consent. The study goals were explained to all of them before giving the consent. All the selected patients underwent primary angioplasty with or without stent placement and were given an appointment for the next study phase.

Phase (2): The studied patients $(\mathrm{N}=59)$ were subjected to the following:

1. Assessment of stroke severity using the NIHSS (total scores: 0-42) were divided in to minor stroke (1-4), moderate stroke (5-15), moderate to severe stroke (16-20), severe stroke (21-42) (Mirjam et al., 2020).

2. Assessment of the disability using Modified Rankin Scale (mRS) (No symptoms at all 0), (No significant disability despite symptoms; able to carry out all usual duties and activities +1 ), (Slight disability; unable to carry out all previous activities, but able to look after own affairs without assistance +2 ), (Moderate disability; requiring some help, but able to walk without assistance +3), (Moderately severe disability; unable to walk and attend to bodily needs without assistance +4) (Severe disability; bedridden, incontinent and requiring constant nursing care and attention +5 ) (Dead +6), (Wagle et al., 2011).

3. Assessment of degree of stenosis using WASID criteria, (Liu et al., 2013).

Phase (3): The studied patients were divided into two groups:

1. Angioplasty treated group: 19 patient treated by ballon angioplasty two types of ballon used (Primary balloon angioplasty which include Drug Eluting Ballon and appollo ballon type).

2. Stent treated group: many types of stent, 40 patients treated by Solitaire stent, Coronary stent, Neuroform stent, lvis jr stent, LEO Baby (Balt) stent, and Lives stent.

Phase (4): The two groups were subjected to:

1. NIHSS to assess neurological deficit and MRS to assess neurological functional disability at 24 hours, 1 month, 6 months, and 12 months postoperatively.

2. Time from qualifying event (Stroke or TIA) to the procedure was recorded, and the patient was given general 
anesthesia or conscious sedation. The procedure performed was either primary angioplasty or stent placement according to location and size of stenosis.

\section{Endovascular treatment modality} included:

1. Primary balloon angioplasty, which include Drug Eluting Ballon and appollo ballon type.

2. Stent type which include, Solitaire stent, Coronary stent, Neuroform stent, lvis jr stent, LEO Baby (Balt) stent, and Lives stent.

Angiographic evaluation of patients was at 6 months and 12-month Postoperatively. Significant postoperative residual stenosis (stenosis $\geq 30 \%$ in the immediate post-operative angiographic images) and binary restenosis (stenosis $\geq 50 \%$ at the time of angiographic follow up after excluding postoperative residual stenosis) were identified as angiographic endpoints.

Clinical evaluation of patients was at 24 hours, 1 month, 6 months, and 12 months post-operative according to NIHSS to assess neurological deficit and MRS to assess neurological functional disability.
The clinical endpoint included the following:

1. Any stroke in the same territory as the presenting event (distal to the target lesion) within 1 year of randomization.

2. Hard TIA in the same territory as the presenting event (distal to the target lesion) between 2 days and 1 year of randomization to avoid misinterpretation of post anesthesia neurological fluctuations.

The study protocol was approved by the Ethics Committee of Al-Azhar Faculty of Medicine on April 2015. The study was performed in accordance with the ethical standards laid down in the 1964 Declaration of Helsinki and its later amendments.

\section{Statistical Analysis:}

Statistical analyses were performed using SPSS (version 19.0; IBM, Armonk, New York). The chi-square test was performed for categorical variables, and $\mathrm{t}$ test or Mann-Whitney U test was used for continuous variables, between the angioplasty-treated group and stenttreated group. A two-tailed $\mathrm{P}$ value $<0.05$ was considered statistically significant. 


\section{RESULTS}

\section{Demographic characteristics and baseline assessment:}

Clinically, the qualifying event to the procedure was stroke in 45 patients (76.3\%), and TIA in 14 patients $(23.7 \%)$. All patients were already receiving antithrombotic therapy and double antiplatelet therapy at the time of the qualifying event. Regarding qualifying event severity, measured by NIHSS, was as follow: 20/59 (33.9\%) mild (NIHSS $<5), 39(66.1 \%)$ moderate (NIHSS=5-14). Preprocedural functional status was evaluated by use of $\mathrm{mRS}$ scale. Thirtynine patients $(66.1 \%)$ had $\mathrm{mRS} \leq 3$. Twenty patients $(33.9 \%)$ had $\mathrm{mRS}>3$. The symptomatic qualifying artery was middle cerebral artery (MCA) in 29 patients $(49.2 \%)$, anterior cerebral artery (ACA) in 2 patients $(3.4 \%)$, petrous part of the internal carotid artery (P-ICA) and MCA in 4 patients $(6.8 \%)$, the supraclinoid part of ICA in 7 patients $(11.8 \%)$, the cavernous part of ICA in 4 patients $(6.7 \%)$.

Angiographically, frequency of stenosis severity were as follow: $70 \%$ stenosis in 5 lesions (8.5\%); 70-79\% stenosis in 7 lesions (11.9\%); $80 \%$ stenosis in 1 lesion $(1.7 \%), 80-89 \%$ stenosis in 16 lesions (27.1\%); and 90$99 \%$ stenosis in 30 lesions $(50.8 \%)$. Lesion length was $<5 \mathrm{~mm}$ in 11 lesions (18.6\%); 5-10 $\mathrm{mm}$ in 20 lesions (33.9\%); and $>10 \mathrm{~mm}$ in 28 lesions $(47.5 \%)$. Regarding circulation status of the stenotic arterial territory according to composite circulation score; Patients with good circulation status (composite circulation score $>3$ ) were 30 patients $(50.8 \%)$. Patients with poor circulation status (composite circulation score $\leq 3$ ) were 29 patients $(49.1 \%)$.

The time from qualifying event to intervention in the angioplasty-treated group was 0 days in 2 patients $(10.53 \%)$; 1-7 days in 1 patient (5.26\%); and > 7 days in 4 patients $(21.05 \%)$. While in the stent-treated group the time was 0 days in 12 patients (12\%); 1-7 days in 9 patients $(22.5 \%)$; and $>7$ days in 19 patients $(47.5 \%)$.

The procedure was done under general anesthesia in 6 patients $(31.57 \%)$ in the angioplasty-treated group and 30 patients in the stent group, and under conscious sedation in 1 patient $(5.3 \%)$ in the angioplasty-treated group and 10 patients $(25 \%)$ in the stent-treated group. 16 patients $(84.2 \%)$ in the angioplasty-treated group had tortuous proximal vessels $(\geq 2$ acute curves) compared to thirty-one patients in the stent-treated group. Prestent angioplasty was performed in 14 patients (35\%). Post-stent angioplasty was performed in four patients $(10 \%)$. The intermediate catheter was used in 12 patients $(30 \%)$. Over-the Wire Exchange was performed in 11 patients $(27.5 \%)$.

Regarding no. of lesion passes, it was single pass in 12 patients $(63.2 \%)$ in the angioplasty-treated group compared to 25 patients $(62.5 \%)$ in the stent group, and multiple passes in 7 patients $(36.8 \%)$ in the angioplasty group compared to 15 patients $(37.5 \%)$ in the stent-treated group. Intraprocedural adverse events occurred in one patient $(5.3 \%)$ in the angioplasty-treated group compared to 12 patients $(30 \%)$ in the stent-treated group $(\mathrm{P}=0.044)$ (Table 1). 
Table (1): Comparison between the studied groups as regard to basic characteristics

\begin{tabular}{|c|c|c|c|c|}
\hline \multicolumn{2}{|c|}{$\begin{array}{ll}\text { Parameters } & \text { Groups } \\
\end{array}$} & $\begin{array}{c}\text { Angioplasty } \\
(\mathrm{n}=19)\end{array}$ & $\begin{array}{c}\text { Stent } \\
(\mathrm{n}=40)\end{array}$ & P-value \\
\hline \multicolumn{2}{|c|}{ Age $($ mean \pm SD) } & $62.32 \pm 9.031$ & $64.30 \pm 8.30$ & \\
\hline \multirow[b]{2}{*}{ Sex } & Female & 9 & 18 & \\
\hline & Male & 10 & 22 & \\
\hline \multicolumn{5}{|l|}{ Clinical Characteristics } \\
\hline \multirow{2}{*}{ Qualifying event } & TIA & $3(15.8 \%)$ & $11(27.5 \%)$ & \multirow{2}{*}{0.514} \\
\hline & Stroke & $16(84.2 \%)$ & $29(72.5 \%)$ & \\
\hline \multirow{2}{*}{$\begin{array}{c}\text { Already receiving } \\
\text { antithrombotic therapy } \\
\text { at time of qualifying } \\
\text { event }\end{array}$} & Mono & $15(78.9 \%)$ & $21(52.5 \%)$ & \multirow[b]{2}{*}{0.085} \\
\hline & Double & $4(21.1 \%)$ & $19(47.5 \%)$ & \\
\hline \multirow{2}{*}{$\begin{array}{l}\text { Stroke severity } \\
\text { (NIHSS) }\end{array}$} & Mild & $6(31.6 \%)$ & $14(35.0 \%)$ & \multirow{2}{*}{0.759} \\
\hline & Moderate & $13(68.4 \%)$ & $26(65.0 \%)$ & \\
\hline \multirow{2}{*}{$\begin{array}{c}\text { Preprocedural } \\
\text { Functional Status }\end{array}$} & $\mathrm{mRs} \leq 3$ & $12(63.2 \%)$ & $27(67.5 \%)$ & \multirow{2}{*}{0.742} \\
\hline & $\mathrm{mRs}>3$ & $7(36.8 \%)$ & $13(32.5 \%)$ & \\
\hline \multirow{6}{*}{$\begin{array}{l}\text { Symptomatic } \\
\text { qualifying artery }\end{array}$} & $\mathrm{ACA}$ & $1(5.3 \%)$ & $1(2.5 \%)$ & \multirow{6}{*}{0.021} \\
\hline & CAVERNOUS ICA & $2(10.5 \%)$ & $2(0.05 \%)$ & \\
\hline & MCA & $10(52.6 \%)$ & $19(47.5 \%)$ & \\
\hline & PET+MCA & $1(5.3 \%)$ & $3(7.5 \%)$ & \\
\hline & Petrous ICA & $1(5.3 \%)$ & $12(30 \%)$ & \\
\hline & SUPRACLINOID & $4(21.1 \%)$ & $3(7.5 \%)$ & \\
\hline \multicolumn{5}{|c|}{ Angiographic Characteristics } \\
\hline \multirow{5}{*}{$\begin{array}{l}\text { Mean percentage } \\
\text { stenosis }\end{array}$} & $70 \%$ & $1(5.2 \%)$ & $4(10 \%)$ & \multirow{5}{*}{0.023} \\
\hline & $70-79 \%$ & $3(15.8 \%)$ & $4(10 \%)$ & \\
\hline & $80 \%$ & $1(5.2 \%)$ & $0(0 \%)$ & \\
\hline & $80-89 \%$ & $1(5.2 \%)$ & $15(37.5 \%)$ & \\
\hline & $90-99 \%$ & $13(68.4 \%)$ & $17(42.5 \%)$ & \\
\hline \multirow{3}{*}{$\begin{array}{l}\text { Mean lesion length } \\
(\mathrm{mm})\end{array}$} & $<5 \mathrm{~mm}$ & $2(10.5 \%)$ & $9(22.5 \%)$ & \multirow{3}{*}{0.026} \\
\hline & $5-10 \mathrm{~mm}$ & $3(15.7 \%)$ & $17(42.5 \%)$ & \\
\hline & $>10 \mathrm{~mm}$ & $14(73.7 \%)$ & $14(35 \%)$ & \\
\hline \multirow{2}{*}{$\begin{array}{l}\text { Circulation status } \\
\text { (composite circulation } \\
\text { score) }\end{array}$} & Good $(>3)$ & $18(94.7 \%)$ & $12(30 \%)$ & \multirow[b]{2}{*}{0.001} \\
\hline & Poor $(\leq 3)$ & $1(5.3 \%)$ & $28(70 \%)$ & \\
\hline \multicolumn{5}{|l|}{ Procedure Characteristics } \\
\hline \multirow{2}{*}{ No. of lesion pass } & Single & $12(63.2 \%)$ & $25(62.5 \%)$ & \multirow[b]{2}{*}{0.961} \\
\hline & Multiple & $7(36.8 \%)$ & $15(37.5 \%)$ & \\
\hline \multicolumn{2}{|c|}{ Intraprocedural adverse events } & $1(5.3 \%)$ & $12(30.0 \%)$ & 0.044 \\
\hline \multirow{3}{*}{$\begin{array}{l}\text { Time from qualifying } \\
\text { event to procedure }\end{array}$} & 0 days & $2(10.53 \%)$ & $12(30 \%)$ & \multirow{3}{*}{0.858} \\
\hline & 1-7 days & $1(5.26 \%)$ & $9(22.5 \%)$ & \\
\hline & $>7$ days & $4(21.05 \%)$ & $19(47.5 \%)$ & \\
\hline \multicolumn{2}{|c|}{ Tortuous Proximal Vessels ( $\geq 2$ acute curve) } & $16(84.2 \%)$ & $31(77.5 \%)$ & 1.00 \\
\hline
\end{tabular}


The most common risk factor among our study population was hypertension in 45/59 patients $(76.3 \%)$ followed by Dyslipidemia 34/59 (57.6\%), Coronary Artery Disease 31/59 (52.5\%), Diabetes mellitus $27 / 59$ (45.8\%), Hyperuricemia
20/59 (33.9\%), Peripheral Vascular Disease 15/59 (25.4\%), Obesity (BMI $\geq$ 30) $12 / 59$ (20.3\%). Smoking history among our study population was as follow: Current 0/59 (0\%) Former 23/59 (39\%), Never 36/59 (61\%) (Table 2).

Table (2): Risk factors

\begin{tabular}{|c|c|c|c|c|c|}
\hline \multicolumn{2}{|l|}{ Parameters } & $\begin{array}{l}\text { All Patients } \\
\quad(\mathrm{n}=59)\end{array}$ & $\begin{array}{l}\text { Angioplasty- } \\
\text { treated group } \\
(n=19)\end{array}$ & $\begin{array}{l}\text { Stent-treated } \\
\text { group }(n=40)\end{array}$ & P-value \\
\hline \multicolumn{2}{|c|}{ Hypertension } & $45(76.3 \%)$ & $15(78.9 \%)$ & $30(75 \%)$ & 1.000 \\
\hline \multicolumn{2}{|c|}{ Diabetes mellitus } & $27(45.8 \%)$ & $7(36.8 \%)$ & $20(50.0 \%)$ & 0.406 \\
\hline \multicolumn{2}{|c|}{ Coronary artery disease } & $31(52.5 \%)$ & $9(47.4 \%)$ & $22(55.0 \%)$ & 0.781 \\
\hline \multicolumn{2}{|c|}{ Dyslipidemia } & $34(57.6 \%)$ & $11(57.9 \%)$ & $23(57.5 \%)$ & 1.000 \\
\hline \multirow{3}{*}{ Smoking } & Never & $36(61 \%)$ & $9(47.4 \%)$ & $27(67.5 \%)$ & \multirow{3}{*}{0.163} \\
\hline & Former & $23(39 \%)$ & $10(52.6 \%)$ & $13(32.5 \%)$ & \\
\hline & Current & $0(0 \%)$ & $0(0 \%)$ & $0(0 \%)$ & \\
\hline \multicolumn{2}{|c|}{ Hyperuricemia } & $20(33.9 \%)$ & $6(31.6 \%)$ & $14(35 \%)$ & 1.000 \\
\hline \multicolumn{2}{|c|}{ Obesity (BMI $\geq 30)$} & $12(20.3 \%)$ & $5(26.3 \%)$ & $7(17.5 \%)$ & 0.497 \\
\hline \multicolumn{2}{|c|}{$\begin{array}{c}\text { Peripheral Vascular } \\
\text { Disease }\end{array}$} & $15(25.4 \%)$ & $7(36.8 \%)$ & $8(20 \%)$ & 0.207 \\
\hline
\end{tabular}

Our analysis showed that there was no statistically significant between the outcome parameters and type of interventional treatment except in restenosis $(\geq 30 \%)$ at median radiological follow-up of 12.5 months. Successful revascularization (Residual stenosis $<30 \%$ ) was obtained in all patients of the angioplasty group (19/19) compared to $92.5 \%$ of patients in the stent group (Pvalue $=0.544)$. After a median clinical follow-up of 17.5 months, 6 patients (31.6 $\%)$ in the angioplasty-treated group had unfavorable outcomes (composite of any death, stroke, and/or TIA), compared to 16 patients $(40 \%)$ in the stent-treated group $(\mathrm{P}$-value $=0.578)$.

At 30 days, fatal hemorrhagic stroke occurred in 2 patients, one $(5.3 \%)$ in the angioplasty-treated group and one $(2.5 \%)$ in the stent-treated group. Fatal ischemic stroke occurred in 3 patients one $(5.3 \%)$ in the angioplasty-treated group and two patients $(5 \%)$ in the stent-treated group.
Three patients had a non-fatal ischemic stroke at 30 days, all of them in the stenttreated group $(7.5 \%) \quad((\mathrm{P}-\mathrm{value}=0.627)$. Between 31 and 90 days, fatal hemorrhagic stroke occurred only in the stent-treated group in 1 patient (2. 5\%), fatal ischemic stroke occurred in 2 patients, one in the angioplasty-treated group $(5.3 \%)$ and one in the stent-treated group $(2.5 \%)(\mathrm{P}-$ value $=0.682)$.

After 90 days, fatal ischemic stroke occurred only in the stent-treated group in 4 patients (10\%); non-fatal ischemic stroke occurred in 6 patients, two $(10.5 \%)$ in the angioplasty-treated group and four patients $(10 \%)$ in the stent-treated group; TIAs also occurred at the same frequencies as non-fatal ischemic stroke $(\mathrm{P}$-value $=0.562)$. Restenosis $(\geq 50 \%)$ at median radiological follow-up of 12.5 months was observed in 9 patients, 6 patients $(31.6 \%)$ in the angioplasty-treated group and 3 patients in the stent-treated group $(\mathrm{P}-$ value $=0.025)($ Table 3$)$. 
Table (3): The incidence of outcome parameters among the study population

\begin{tabular}{|c|c|c|c|}
\hline $\begin{array}{ll}\text { Parameters } & \text { Groups } \\
\end{array}$ & $\begin{array}{l}\text { Angioplasty-treated } \\
\text { group }(\mathrm{n}=19)\end{array}$ & $\begin{array}{c}\text { Stent-treated group } \\
(\mathrm{n}=40)\end{array}$ & P-value \\
\hline $\begin{array}{l}\text { Successful revascularization } \\
\text { (Residual stenosis }<30 \%)\end{array}$ & $19(100 \%)$ & $37(92.5 \%)$ & 0.544 \\
\hline $\begin{array}{l}\text { Unfavorable outcome at median } \\
\text { clinical follow-up of } 17.5 \\
\text { months }\end{array}$ & $6(31.6 \%)$ & $16(40.0 \%)$ & 0.578 \\
\hline \multicolumn{4}{|c|}{ Any death, stroke, and/or TIA (0-30 days) } \\
\hline None & $17(89.5 \%)$ & $34(85.0 \%)$ & \multirow{4}{*}{0.627} \\
\hline Fatal haemorrhage stroke & $1(5.3 \%)$ & $1(2.5 \%)$ & \\
\hline Fatal Ischemic stroke & $1(5.3 \%)$ & $2(5 \%)$ & \\
\hline Non-fatal ischemic stroke & $0(0 \%)$ & $3(7.5 \%)$ & \\
\hline \multicolumn{4}{|c|}{ Any death, stroke, and/or TIA (31-90 days) } \\
\hline None & $18(94.7 \%)$ & $38(95.0 \%)$ & \multirow{3}{*}{0.682} \\
\hline Fatal haemorrhagic stroke & $0(0 \%)$ & $1(2.5 \%)$ & \\
\hline Fatal ischemic stroke & $1(5.3 \%)$ & $1(2.5 \%)$ & \\
\hline \multicolumn{4}{|c|}{ Any death stroke and or TIA (> 90 days) } \\
\hline None & $15(78.9 \%)$ & $28(70.0 \%)$ & \multirow{4}{*}{0.562} \\
\hline Fatal hemorrhagic stroke & $0(0 \%)$ & $4(10.0 \%)$ & \\
\hline Non-fatal ischemic stroke & $2(10.5 \%)$ & $4(10.0 \%)$ & \\
\hline TIA & $2(10.5 \%)$ & $4(10.0 \%)$ & \\
\hline
\end{tabular}

Male patient 45 years old hypertensive presented by recurrent ischaemic stroke on double antiplatelet and full dose statin, angiography showed right MCA M1 stenosis direct stenting of MCA without residual stenosis and complete filling of tributaries of MCA vessel (Figure 1). 

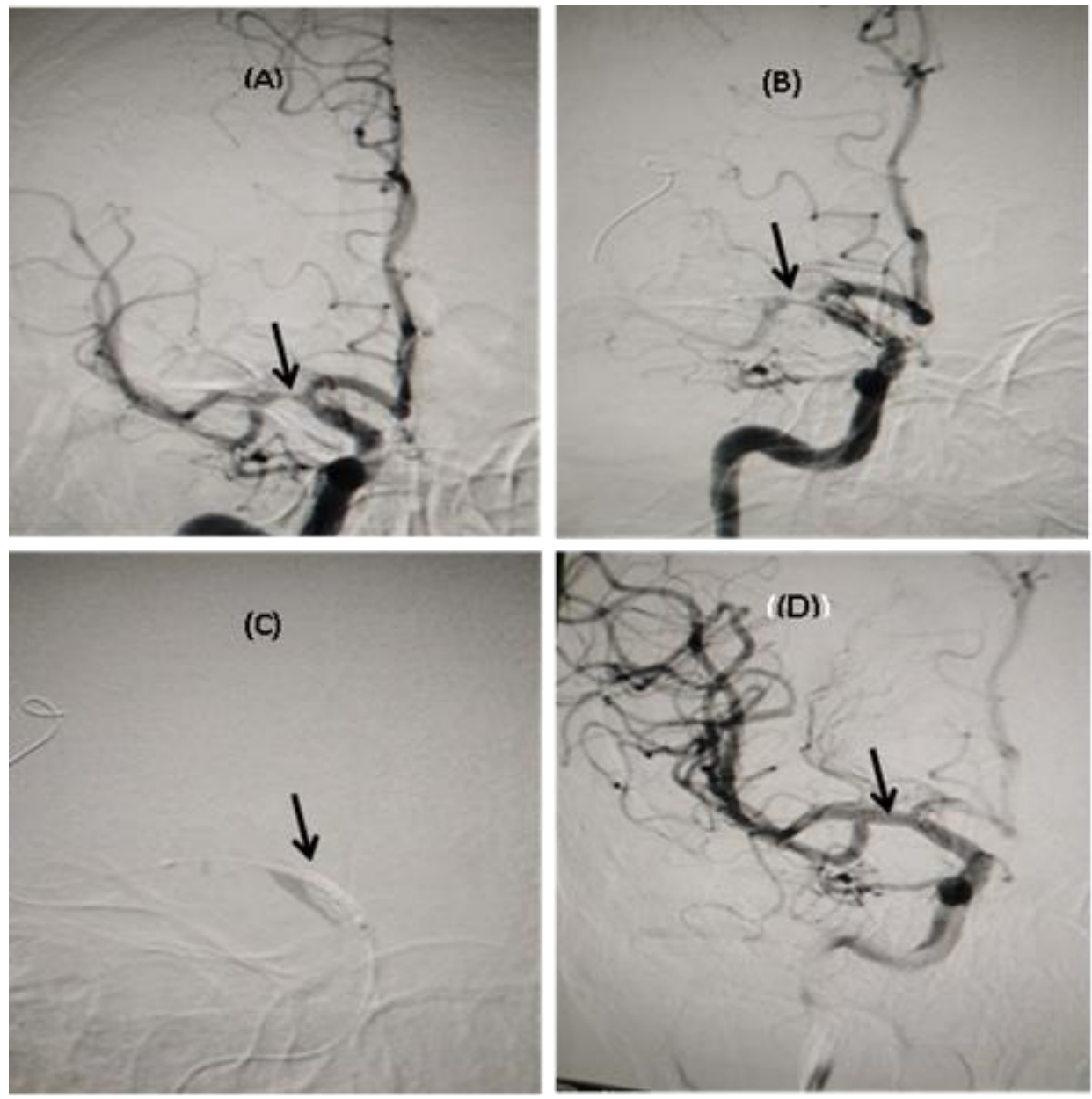

Figure (1): Direct stent placement in RT MCA stenosis using coronary stent $(3 \times 18)$ over microwire.

\section{(A): M1 Stenosis}

(B): Angioplasty of stenotic vessels

(C): Angioplasty and Stenting

(D): Refilling of blood flow after stentng

\section{DISCUSSION}

Atherosclerotic intracranial arterial stenosis is a primary cause of TIA and ischemic stroke worldwide, accounting for up to 30 to $50 \%$ of ischemic stroke in Asia population (Lanas and Seron, 2021). Up to now, medical management, antiplatelet drugs and high-intensity statin therapy with risk factor modification are still recommended as the mainstays of management in patients with symptomatic ICAD to prevent TIA and stroke.
Aggressive medical management of risk factors such as HTN, Hyperlipidemia, $\mathrm{DM}$, and smoking cessation is an essential component of the regimen (Chimowitz et al., 2011-a).

However, despite intensive medical management, the risk of recurrent TIA and stroke is high and was still noticed in high-risk patients with symptomatic intracranial stenosis $>70 \% \quad(70-99 \%)$ (Chimowitz et al., 2011-b). This cohort of patients was considered to be refractory to 
Aggressive medical management. In the WASID trial (Warfarin-Aspirin Symptomatic Intracranial Disease), serious stenosis $(>70 \%)$ and bad collaterals were linked to increased risk of stroke recurrence in patients with ICAD (Dankbaar et al., 2018).

Although the VISSIT and SAMMPRIS trials supported Aggressive medical treatment alone compared to endovascular Approaches, both randomized controlled trials (RCT) were criticized due to errors relating to patient-, intervention-, and operator-related issues (Zaidat et al., 2015).

We present the angiographic and clinical data of 59 patients (32 males and 27 females) treated with different modalities of endovascular intervention (intracranial angioplasty with or without stenting). In this prospective study, we found that intracranial angioplasty with or without stenting for management of symptomatic intracranial atheromatous disease associated with a High rate of technical success. Successful revascularization was obtained in 56 patients from $59 \quad(100 \%$ in the angioplasty-treated group and $92.5 \%$ in the stent-treated group). However, restenosis (Residual stenosis $>30 \%$ ) at median radiological follow-up of 12.5 months was statistically significant in the angioplasty-treated group compared to the stent-treated group $(P=0.02)$. In Terada et al. restenosis reported in $26.7 \%$ in the angioplasty-treated group compared to $0 \%$ in the stent-treated group 26. In another study that investigates the restenosis after carotid angioplasty (with or without stent), 9.2\% of patients experienced restenosis during a median follow up of 12 months and authors found that angioplasty without stent considered independent risk predictors for restenosis (Zapata et al., 2016).

Many risk factors may be a trigger for restenosis. Brott et al reported that that dyslipidemia, female gender, diabetes mellitus (DM), were independent predictors of restenosis after carotid angioplasty and stenting (CAS) (Brott et al., 2010). Zapata-Arriaza et al. reported that hypertension could stimulate inflammation and neointimal proliferation and trigger endothelial dysfunction at the site of stent placement. Recently, another study reported that Patients with cardiovascular disease had higher chances of restenosis (Daou et al., 2016). Banerjee and Chimowitz (2017) which investigated the relationship between hypertension and recurrence of stroke in patients with atherosclerotic intracranial arterial stenosis. They found that patients with intracranial stenosis, hypertension is associated with a high risk of ischemic stroke and stroke in the territory of the stenotic vessel. Despite all these predictors for restenosis, our data showed no statistical significance between the two compared groups in the different types of risk factors suggesting that one dependent risk factor has no impact on the rate of stenosis but a combination of different types of risk factors.

Compared to angiographic data, the clinical adverse events (stroke, TIA, or death) is not good; Nearly One-Third of the patients in both groups $(31.6 \%$ in the angioplasty-treated group, $40 \%$ in the stent-treated group) had unfavorable outcome after a median clinical follow-up of 17.5 months, however, there is no 
privilege of one group over another. In WASID trial 31. Patients with mean percentage stenosis $>70 \%$ have a high risk for stroke in the territory of the stenotic vessel. In our study, all patients have stenosis more than $70 \%$ which may explain the incidence of a clinical adverse event in the long term. Another explanation is mean lesion length, in our data almost $81 \%$ of patients have mean length lesion $>5 \mathrm{~mm}$ which may affect the long-term outcome.

Also, the intraprocedural adverse event was high in the stent-treated group compared to the angioplasty-treated group. Jiang et al., (2011) reported that CAS for symptomatic intracranial stenosis is feasible However, severe vessels tortuosity is an independent predictor of stent failure. Vessels tortuosity rises the complexity and decreases the success rate of endovascular therapy by generating difficulty in wiring the artery and delivering angioplasty equipment. Besides vessels tortuosity, there are many other explanations for these adverse events including technical problems, mean percentage stenosis, mean lesion length, circulation status, and symptomatic qualifying artery, preprocedural function status, and antithrombotic therapy.

\section{Limitations of study:}

There are numbers of potential limitations. First, this was not a randomized study and the assessment of outcome could not be blinded however, that was not expected to introduce a major bias because of the objectivity of the outcome. Second, angioplasty and/or stenting were performed at the discretion of the treating neurologist, and confounding factors could have been introduced during the selection process of the patient Third, a relatively small sample size. Finally, the patients were recruited in a single Centre which may be subjected to a degree of selection bias.

\section{CONCLUSION}

Endovascular therapy with a cautious selection of patients, suitable type of techniques, and experienced operators (Neurologist) may decrease the risks of intraoperative complications and provide greater benefit for symptomatic ICAS patients. Therefore, we should pay more attention to these aspects in the future. We also need RCTs that investigate the safety and efficacy of different endovascular modalities for the management of a symptomatic intracranial atherosclerotic disease.

Disclosure of interest: The authors declare that no potential conflicts of interest concerning this paper to be disclosed and they did not receive financial support from any third party.

\section{REFERENCES}

1. Alexander MJ. (2012): Intracranial stenting for intracranial atherosclerotic disease: still much to learn. Journal of Neurointerventional Surgery, 4(2):85-86.

2. Alexander MJ, Zauner A, Chaloupka JC, Callison RC and John C. (2019): WEAVE Trial, Final Results in 152 On-Label Patients. Stroke, 50(4):889-894.

3. Arenillas JF. (2011): Intracranial atherosclerosis current concepts. Stroke, 42(1Suppl):S20-3.

4. Brott TG, Hobson RW 2nd, Howard G, Roubin GS and Clark W.M. (2010): Stenting versus endarterectomy for treatment of carotid-artery stenosis. The New England Journal of Medicine, 363(1):11-23.

5. Chimowitz MI, Lynn MJ, Turan TN, Derdeyn CP, Derdeyn CP, Fiorella D and 
Lane B.F. (2011-a): Stenting versus aggressive medical therapy for intracranial arterial stenosis . The New England journal of medicine, 365(11):993-1003.

6. Chimowitz MI, Lynn MJ, Turan TN, Derdeyn CP, Fiorella D, and Lane B.F. (2011-b): Design of the stenting and aggressive medical management for preventing recurrent stroke in intracranial stenosis trial. Journal of stroke and cerebrovascular diseases : the official journal of National Stroke Association, 20(4):357368 .

7. Clark SE. and Aziz F. (2017): Differential Diagnosis for Lower Extremity Ischemia and Ulcerations: Focus on Non-atherosclerotic Etiologies BT - Critical Limb Ischemia: Acute and Chronic. In: Dieter RS, Dieter Raymond A. J, Dieter Raymond A. III, Nanjundappa A, eds. Cham: Springer International Publishing, 33(5): 95-107.

8. Dankbaar JW, Kerckhoffs KGP, Alexander DH, Irene C. and Schaaf L. (2018): Internal Carotid Artery Stenosis and Collateral Recruitment in Stroke Patient. Clinical Neuroradiology, 28(3): 339-44

9. Daou B, Chalouhi N, Starke RM, Barros G., Nohra C., Guilherme $B$ and Stayropoula T. (2016): Predictors of restenosis after carotid artery stenting in 241 cases. Journal of NeuroInterventional Surgery, 8(7):677-679.

10. Jiang W-J, Yu W, Du B, Gao F. and Cui LY. (2011): Outcome of patients with $\geq 70 \%$ symptomatic intracranial stenosis after Wingspan stenting. Stroke, 42(7):1971-1975.

11. Lanas F and Seron P. (2021): Facing the stroke burden worldwide. The Lancet Global Health, 9(3):e235-e236.

12. Liu Qi, Huang J, Degnan AJ, Chen S., Gillard JH, Juang J, Jonathan HG and Zhona Z. (2013): Comparison of HighResolusion MRI with CT Angiography and Digital Subtraction Angiography for the Evaluation of Middle Cerebral Artery Atherosclerotic Steno-Occlusive Diseases. The International Journal of Cardiovascular Imaging, 29(7):1491-98.
13. Maida CD, Norrito RL, Daidone $M$, Tuttolomondo A. and Pinto A. (2020): Neuroinflammatory Mechanisms in Ischemic Stroke: Focus on Cardioembolic Stroke, Background, and Therapeutic Approaches. International Journal of Molecular Sciences, 21(18), 6454-6465.

14. Mei J, Deng $Y$, Chen $Y$ and Yang $H$. (2017): Comparative effect of pecutaneous transtuminl angioplasty and stenting (PTAS) plus medical therapy treatment versus medical therapy treatment for intracranial atherosclerotic stenosis: Evidence from a meta-analysis involving ten studies. International Journal of Clinical and Experimental Medicine, 10(5):7335-7348.

15. Merjam RH., Heinrich PM., Fiehler J and Thomalla G. (2020): IntracraniaL Stenting after failed thrombectomy in patients with moderately severe stroke, Front Neurol., 11(97):318-326.

16. Miao Z, Zhang Y, Shuai J, Jiang C, Zhu Q and Chen K. (2015): Thirty-Day Outcome of a Multicenter Registry Study of Stenting for Symptomatic Intracranial Artery Stenosis in China. Stroke, 46(10):2822-2829.

17. Ritz K, Denswil NP, Stam OCG, van Lieshout JJ and Daemen MJAP. (2014): Cause and mechanisms of intracranial atherosclerosis. Circulation, 130(16):14071414.

18. Wagle J., Farner L., Flekkoy K., Wyller TB, Brvniar F and Sandvik L. (2011): Early Post-Stroke Cognition in Stroke Rehabilitation Patient Predicts Functional Outcome at 13 Months. Dementia and Geriatric Cognitive Disorders, 31(5):379-87.

19. Zaidat OO, Fitzsimmons BF, Woodward BK and Zhigang W. (2015): Effect of a balloon-expandable intracranial stent vs medical therapy on risk of stroke in patients with symptomatic intracranial stenosis: the VISSIT randomized clinical trial. JAMA, 313(12):1240-1248.

20. Zapata AE, Moniche F, González A and Bustamante A. (2016): Predictors of Restenosis Following Carotid Angioplasty and Stenting. Stroke, 47(8):2144-2147. 
تقييم توسيع ضيق الثرايين المخية المسببة لأعر اض بالبالون بدون أو مع تركيب دئ دعامة

علي حسنين علي،، عمرو السيد سالم2، خالد محمد صبح2، شريف محمود الثناذلي1،

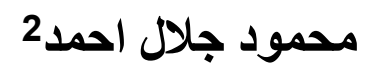

قسم طب المخ و الأعصاب، كلية طب الأزهر ( دمياط1، القاهرة2)

E-mail: dr.ali3012@gmail.com

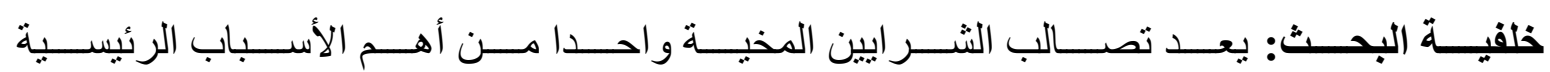

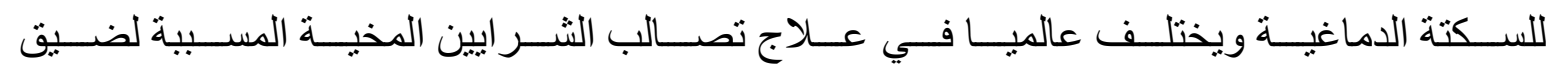

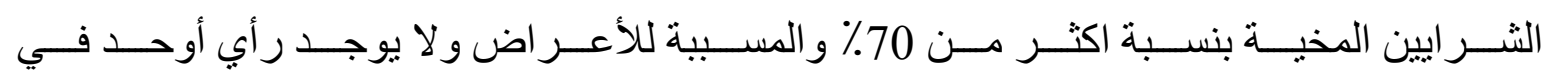

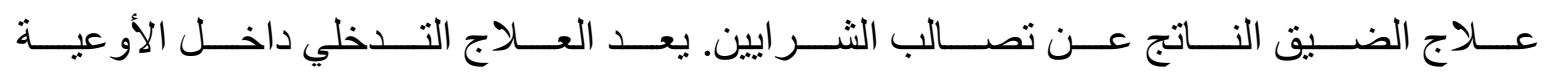

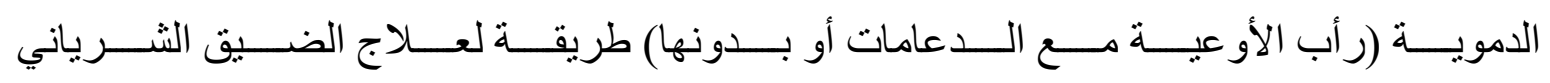

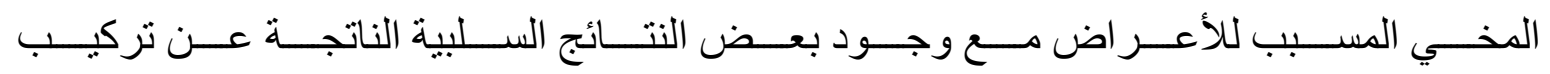

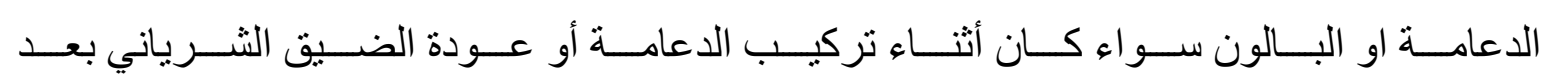
البالون أو بعد تركيب الدعامة مباشرة أو بعد فنرة زمنية.

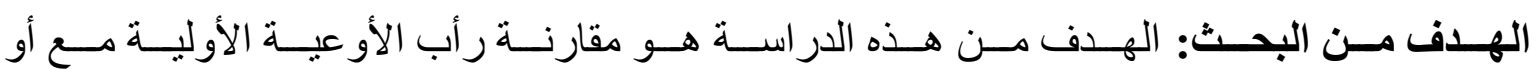

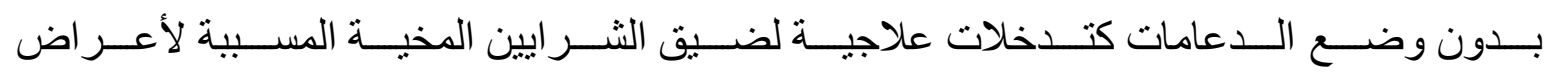
وفقا للنتائج السريرية ومعدل عودة الضيق الثرياني.

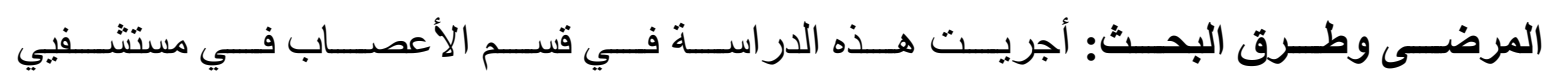

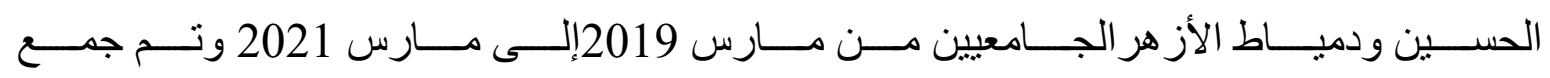

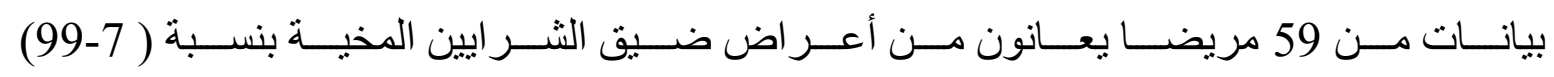

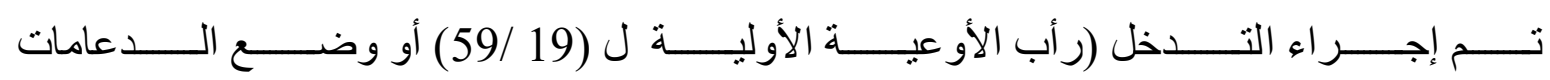

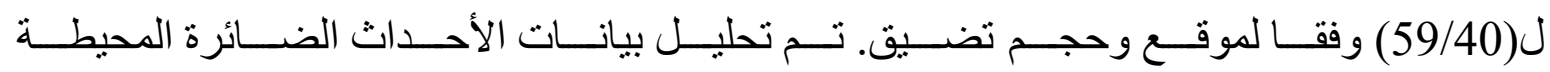
بالطبيعة ونتائج المتابعة السريرية و العائية.

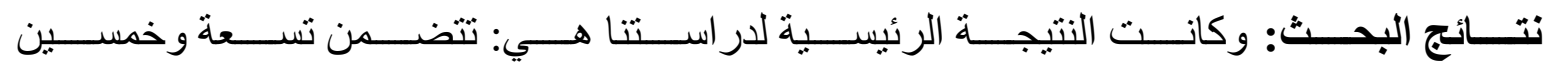

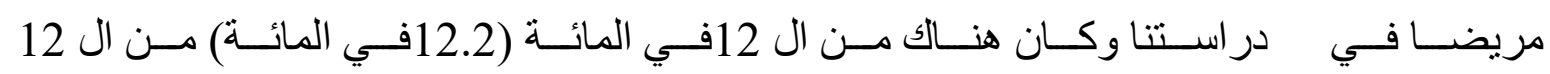

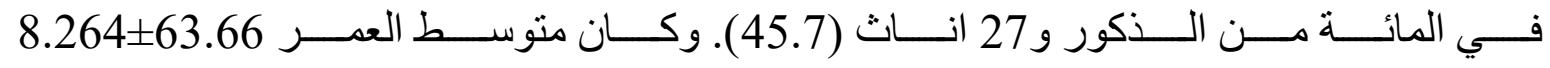




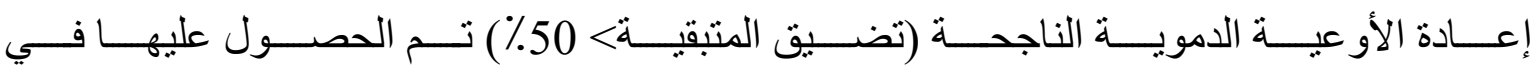

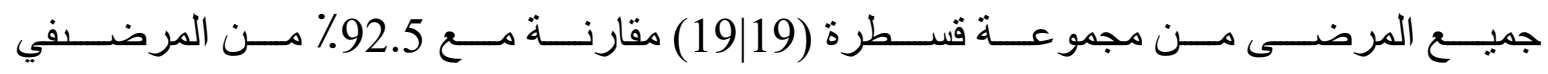
مجمو عة الدعامات (P-value 544).

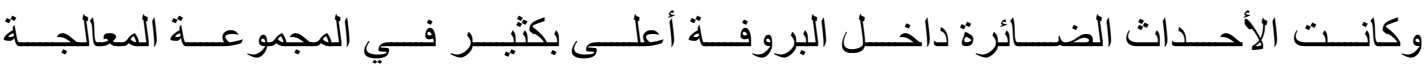

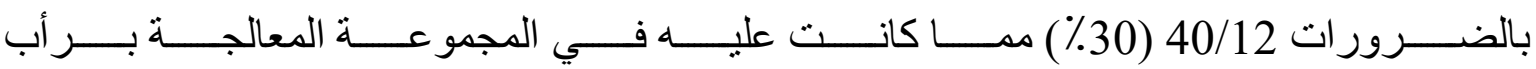

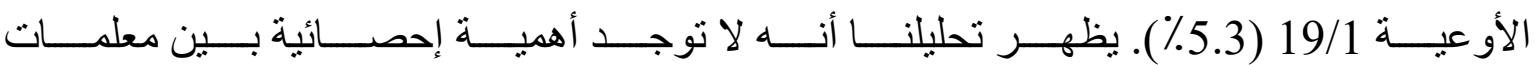

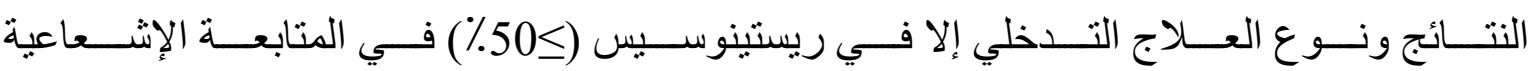

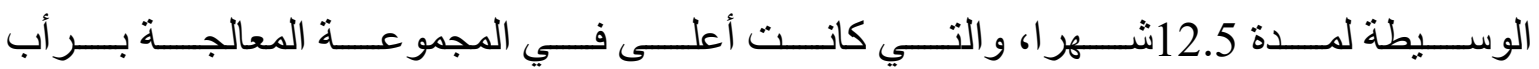

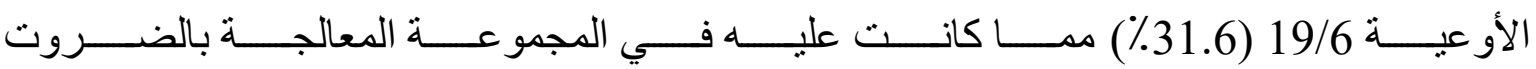
. $(\% .7 .5) 40 / 3$

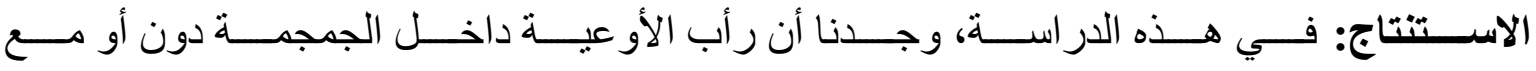

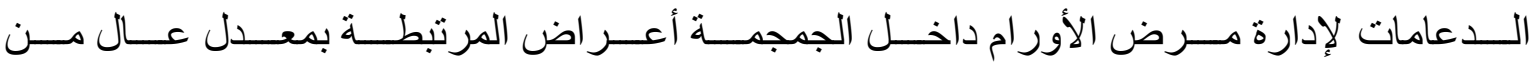

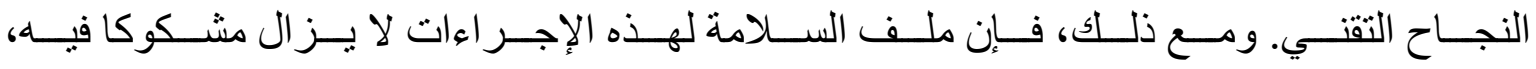

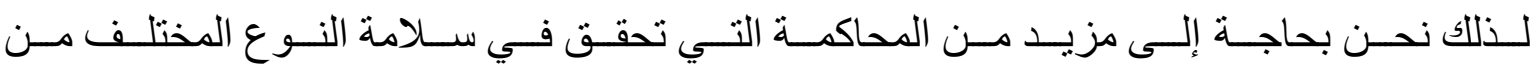
طر ائق الأوعية الدموية لإدارة ضيق الثرايين المخية المسببة لأعر اض.

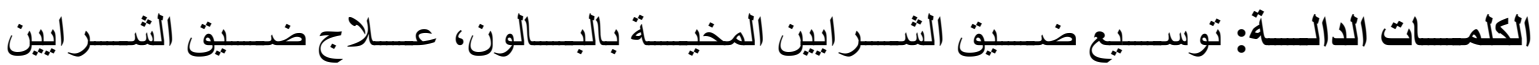
المخية بالدعامات، تصالب الثر ايين المخية. 